\title{
New co-crystal and salt form of sulfathiazole with carboxylic acid and amide
}

\author{
RANITA SAMANTA, SHIPRA KANAUJIA and C MALLA REDDY* \\ Department of Chemical Sciences, Indian Institute of Science Education and Research (IISER) Kolkata \\ Mohanpur Campus, Mohanpur 741252 India \\ e-mail: cmallareddy@gmail.com
}

MS received 14 May 2014; revised 8 July 2014; accepted 8 July 2014

\begin{abstract}
One co-crystal and one salt of an antibacterial drug sulfathiazole with 4-aminobenzamide and 2,4dinitrobenzoic acid have been synthesized. These new forms are characterized by single crystal X-ray diffraction, infrared spectroscopy, differential scanning calorimetry (DSC) and thermogravimetric analysis (TGA). In solid state, sulfathiazole preferentially adopts the imidine tautomeric form.
\end{abstract}

Keywords. Co-crystal; pharmaceutical; salt; tautomerism; sulfathiazole; synthon.

\section{Introduction}

Crystal engineering is defined as the understanding of intermolecular interactions in the context of crystal packing and the utilization of such understanding in the design of new solids with desired physical and chemical properties. ${ }^{1}$ In recent times this approach has been shown to be very useful for obtaining co-crystal and salt forms of active pharmaceutical ingredients (APIs) with improved physicochemical properties compared to the original APIs, without affecting the pharmacological behaviour. ${ }^{2}$ In this regard, supramolecular synthon approach is very useful as it provides the basis for selection of co-formers. ${ }^{3}$ Hence it is important to understand the role of competing functional groups and their preference for forming supramolecular synthons in a complex crystalline environment. In this context, sulfa drugs, such as sulfathiazole, sulfamethazine, etc., with high conformational flexibility have always been attractive, as they possess several strong hydrogen bonding groups such as $\mathrm{SO}_{2}, \mathrm{NH}_{\text {(sulfonamide) }}$ and $\mathrm{NH}_{2} \cdot{ }^{4,5}$ The aromatic groups on the drug molecules also play a key role by forming $\pi$-stacking interactions with aromatic co-former and thus promote the formation of molecular complexes, such as co-crystals, salts, solvates, etc.

Sulfathiazole (STZ) is a short acting sulfa drug and has a spectrum of antimicrobial actions. It has two types of strong donors (amine $\mathrm{NH}_{2}$ and a sulfonamide $\mathrm{NH}$ ) with a total of three acidic protons. ${ }^{6}$ There are two types of strong acceptors, two sulfoxy O-atoms, one amine $\mathrm{N}$ atom. Here we present two new multicomponent forms

*For correspondence of STZ, namely a co-crystal with 4-aminobenzamide (4AMB), and a salt with 2,4-dintrobenzoic acid (DNB).

\section{Experimental}

\subsection{Materials}

Sulfathiazole drug, the co-crystal former and salt former were purchased from Sigma-Aldrich. Commercially available solvents were used without further purification.

\subsection{Single crystal preparation}

Sulfathiazole drug and co-former in a 1:1 stoichiometric ratio was taken in a $10 \mathrm{~mL}$ conical flask followed by addition of ethanol. The suspension was heated until a clear solution was obtained. The solution was left for slow evaporation at ambient condition. Single crystals suitable for X-ray diffraction studies were obtained in approximately 5-7 days.

\subsection{Crystallography}

Co-crystal and salt of sulfathiazole were individually mounted on a glass pipe. Intensity data were collected on an Agilent SuperNova system with graphite monochromatic Mo $\mathrm{K} \alpha$ radiation at $100 \mathrm{~K}$. Data reduction was done using CrysAlisPro software. Crystal structures were solved by direct method using SHELXL-97 and refined by full matrix least square on $F^{2}$ with anisotropic displacement parameters for all non $\mathrm{H}$ atoms using SHELXL-97. 


\subsection{Differential scanning calorimetry (DSC)}

DSC was performed on a Mettler-Toledo DSI1 STAR ${ }^{\mathrm{e}}$ instrument. Accurately weighed samples (2-3 mg) were placed in hermetically sealed aluminum crucibles (40 $\mu \mathrm{L}$ ), with a pin hole on lid, and scanned from 30 to $300^{\circ} \mathrm{C}$ at a heating rate of $5^{\circ} \mathrm{C} / \mathrm{min}$ under a dry nitrogen atmosphere.

\subsection{Thermogravimetric analysis (TGA)}

TGA was done on a Mettler-Toledo TGA/SDTA $85^{\text {le }}$ instrument. Approximately (5-6 mg) of the sample was added to an aluminum crucible and heated from 30 to $300^{\circ} \mathrm{C}$ at a rate of $10^{\circ} \mathrm{C} / \mathrm{min}$ under continuous nitrogen purge.

\subsection{IR spectroscopy}

Transmission infrared spectra of the solids were obtained using a Fourier-transform infrared spectrometer. $\mathrm{KBr}$ samples ( $2 \mathrm{mg}$ in $20 \mathrm{mg}$ of $\mathrm{KBr}$ ) were prepared and 10 scans were collected at $4 \mathrm{~cm}^{-1}$ resolution for each sample. Spectra were measured over a range of $4000-400 \mathrm{~cm}^{-1}$.

\section{Results and Discussion}

\subsection{Sulfathiazole/2,4-dinitrobenzoic acid (1:2) salt (STZ/DNB)}

The salt, STZ/DNB, crystallizes in the triclinic $P-1$ space group with one molecule of STZ and two molecules of DNB in the asymmetric unit. Here the sulfathiazole molecule, which adopts a $\mathrm{V}$-shape conformation, exists in imidine tautomeric form due to the transfer of proton from sulfonamide $\mathrm{NH}$ to thiazole ring $\mathrm{N}$-atom (scheme 1). On the other hand, the intermolecular proton transfer from carboxylic acid group of one DNB molecule to the $\mathrm{NH}_{2}$ group of the $\mathrm{STZ}$ molecule leads to the formation of the salt. It is generally suggested that a minimum of $3 p \mathrm{Ka}$ difference $(\Delta p \mathrm{Ka})$ between API and co-former (acid-base pair) is required for an assured salt formation, while a co-crystal is formed when the $\Delta p \mathrm{Ka}<0$ and either a co-crystal or salt form may result when the $\Delta p \mathrm{Ka}$ is between 0 and 3. ${ }^{7}$ Hence, here as the $\Delta p \mathrm{Ka}$ between STZ $(p \mathrm{Ka}=7.2)^{8}$ and DNB $(p \mathrm{Ka}=1.43)^{9}$ is 5.77 , the formation of salt instead of the neutral co-crystal form is not surprising.

In the structure, a trimer is formed, via cyclic synthon $1\left(\mathrm{~N}(13)-\mathrm{H}(13) \cdots \mathrm{O}(30)\right.$; $\left.d / \AA, \theta /{ }^{\circ}: 1.91 \AA, 175^{\circ}\right)$; $\mathrm{N}(11)-\mathrm{H}(11 \mathrm{~B}) \cdots \mathrm{O}(31) ; 1.78(3) \AA$, $\left.172(3)^{\circ}\right) \mathrm{N}(11)-$ $\left.\mathrm{H}(11 \mathrm{~A}) \cdots \mathrm{N}(10) ; 2.04(3) \AA, 179(4)^{\circ}\right)$, by involving the
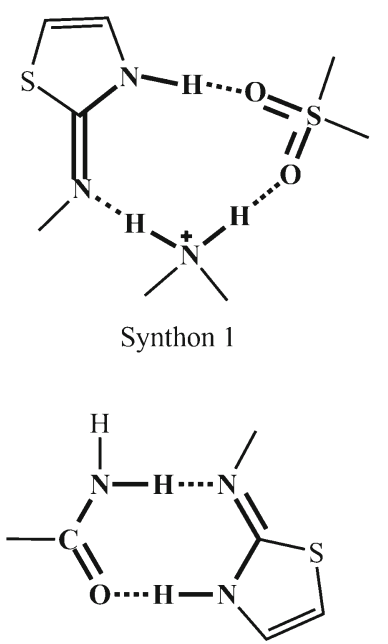

Synthon 3
Synthon 1

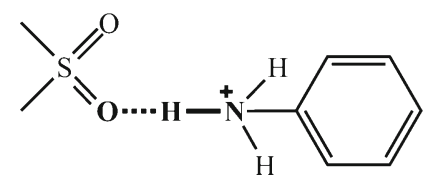

Synthon 2

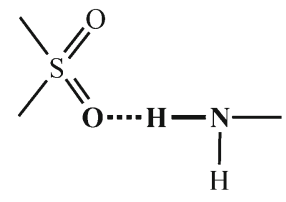

Synthon 4
Scheme 1. Synthons anticipated and/or observed in the STZ co-crystals.

carboxylate of a DNB molecule and with the imidine site and $\mathrm{NH}_{3}^{+}$groups of two STZ molecules, respectively (figure 1a). The remaining and third proton of the $\mathrm{NH}_{3}^{+}$group interacts with sulfoxy O-atom $(\mathrm{N}(11)$ $\mathrm{H}(11 \mathrm{C}) \cdots \mathrm{O}(9)$; $\left.1.94(4) \AA, 166(3)^{\circ}\right)$ to form the synthon 2 , eventually leading to the formation of 1D tape along $a$-axis (figure $1 \mathrm{~b}$ ). The $1 \mathrm{D}$ tapes are stabilized by $\pi$-stacking interactions by the thiazole groups of adjacent 1D tapes and benzene rings of the DNB molecules, which are sandwiched in between the layers of parallel 1D tapes of STZ molecule (figure 1b).

\subsection{Sulfathiazole/4-aminobenzamide (1:1) (STZ/4ABM)}

The co-crystal STZ/4ABM crystallizes in the monoclinic $P 2_{1} / c$ space group with one molecule of each STZ and 4ABM in asymmetric unit. Here, we are unable to justify the formation of co-crystal based on the $\Delta p \mathrm{Ka}$ rule as we could not obtain the $p \mathrm{Ka}$ value of 4ABM. However, the formation of co-crystal here is understandable as it is difficult to ionize amide group due to the low acidity of N-H groups. In the co-crystal, sulfathiazole exists in imidine tautomeric form that results from the intramolecular transfer of proton from sulfonamide $\mathrm{NH}$ to thiazole ring nitrogen. The STZ molecule offers the imidine site for binding with the amide group of 4ABM via synthon $3(\mathrm{~N}(1)-\mathrm{H}(1 \mathrm{~B}) \ldots$ $\mathrm{O}(3) ; 1.94 \AA, 171^{\circ} ; \mathrm{N}(4)-\mathrm{H}(4 \mathrm{~B}) \cdots \mathrm{N}(2) ; 2.15(2) \AA$, $\left.168(2)^{\circ}\right)$ (see scheme 1). The $p$-amino group of 4ABM interacts with the $\mathrm{O}=\mathrm{C}_{(\text {amide) }}$ of another $4 \mathrm{ABM}$ and $\mathrm{O}$ atom of $\mathrm{SO}_{2}$ group of STZ. The STZ molecules interact 


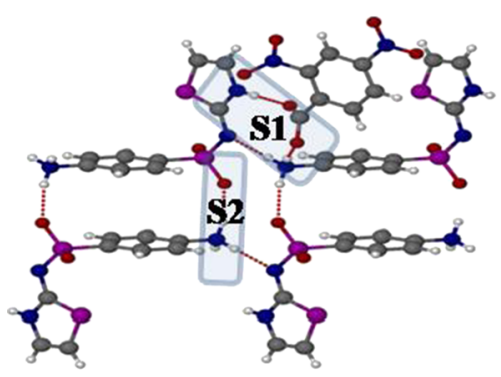

(a)

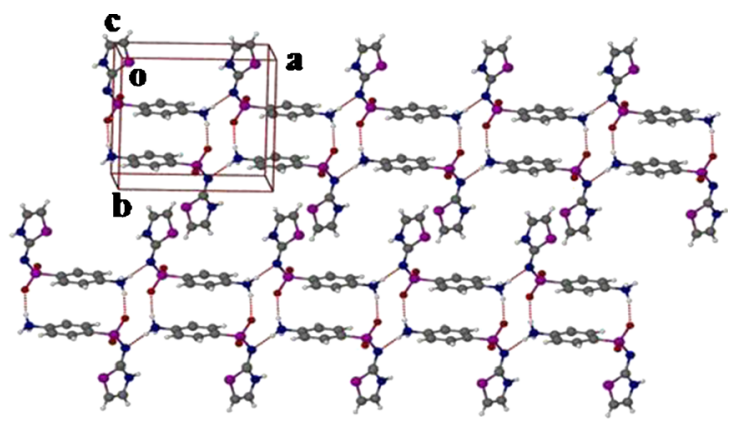

(b)

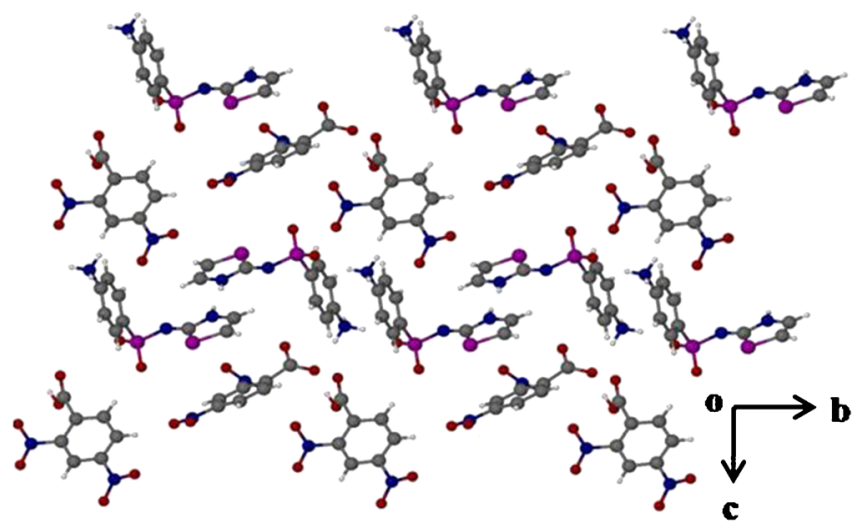

(c)

Figure 1. Crystal packing in sulfathiazole/2,4-dinitrobenzoic acid (1:2) salt (STZ/DNB). (a) Formation of a trimer synthon 1 by two STZ and one DNB molecules, and synthon 2 between $\mathrm{NH}_{3}{ }^{+}$and $\mathrm{O}_{\text {(sulfoxy) }}$ groups. (b) Formation of 1D tapes by STZ molecules via synthon 1 and synthon 2 (the co-former, DNB, molecules are not shown for clarity) (c) Crystal structure viewed along $a$-axis to show the packing of co-former molecules with respect to the parallel 1D tapes.

via synthon $4\left(\mathrm{~N}(3)-\mathrm{H}(8 \mathrm{~B}) \cdots \mathrm{O}(1) ; 2.47 \AA, 162^{\circ}\right)$; $\mathrm{N}(3)$ $\left.\mathrm{H}(3 \mathrm{~B}) \cdots \mathrm{O}(1) ; 2.14(3) \AA, 149(3)^{\circ}\right)$ that leads to the formation of $2 \mathrm{D}$ sheets with a parquet floor network, as shown in figure $2 \mathrm{~b}$. The $2 \mathrm{D}$ sheets are further connected via $\mathrm{N}-\mathrm{H} \cdots \mathrm{O}$ hydrogen bonds extending the network in the third dimension.

As the STZ molecules in both the salt and co-crystal studied here, exist in the imidine tautomeric form ${ }^{10}$ we carried out a Cambridge Crystallographic Database (CSD, version 5.35) search to examine the tautomerism in the earlier reported structures. A search with filters: 1) $3 \mathrm{D}$ coordinates determined, 2) $\mathrm{R}$ factor $<=0.075$, 3) not disordered and 4) no errors found 30 reports of the STZ structures. Notably in all the cases, the STZ molecule existed in imidine tautomeric form, but never in amidine form. Hence this suggests a strong preference of STZ drug for the imidine tautomeric form. In our earlier study, we reported such a preference in succinylsulfathiazole,$^{10}$ which also showed a strong bias for the imidine tautomeric form in all its reported solid-state structures.

\subsection{Infrared spectroscopy}

Formation of new solid forms is studied by infrared spectroscopy. Comparison of spectra of the pure initial co-formers and the new forms clearly demonstrate the peak shift for major peaks, such as $-\mathrm{NH}_{2},-\mathrm{C}=\mathrm{O}$, etc., peaks of acid and amide groups in the co-former (figures S1 and S2).

\subsection{Thermal Analysis}

To study the thermal behaviour of the new forms with respect to API, DSC and TGA, experiments were carried out, which are presented in figure 3. DSC monitors heat flow, associated with the effect of phase transition and chemical reactions as a function of temperature. The melting transition temperatures of the cocrystal and salt forms were distinct from either of the individual components confirming the formation of new phases. The DSC thermogram of STZ/4ABM co-crystal showed a single, melting endotherm at $190^{\circ} \mathrm{C}$, while the 


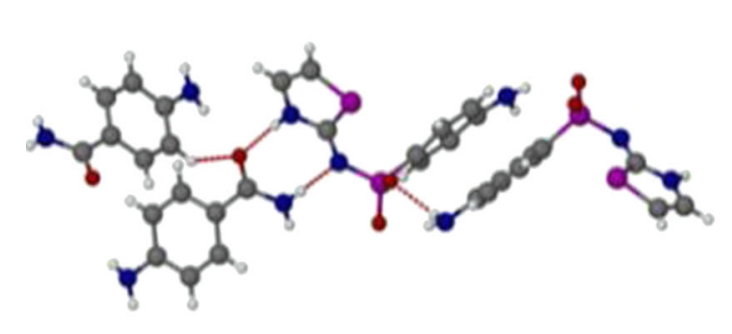

(a)

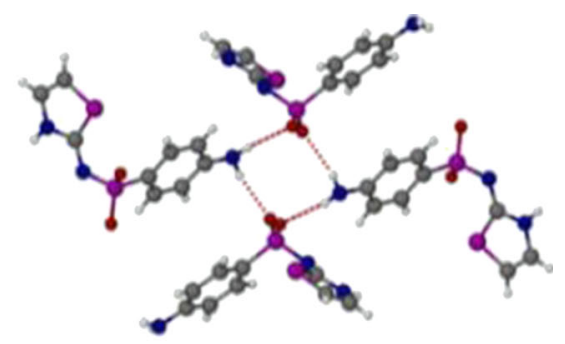

(b)

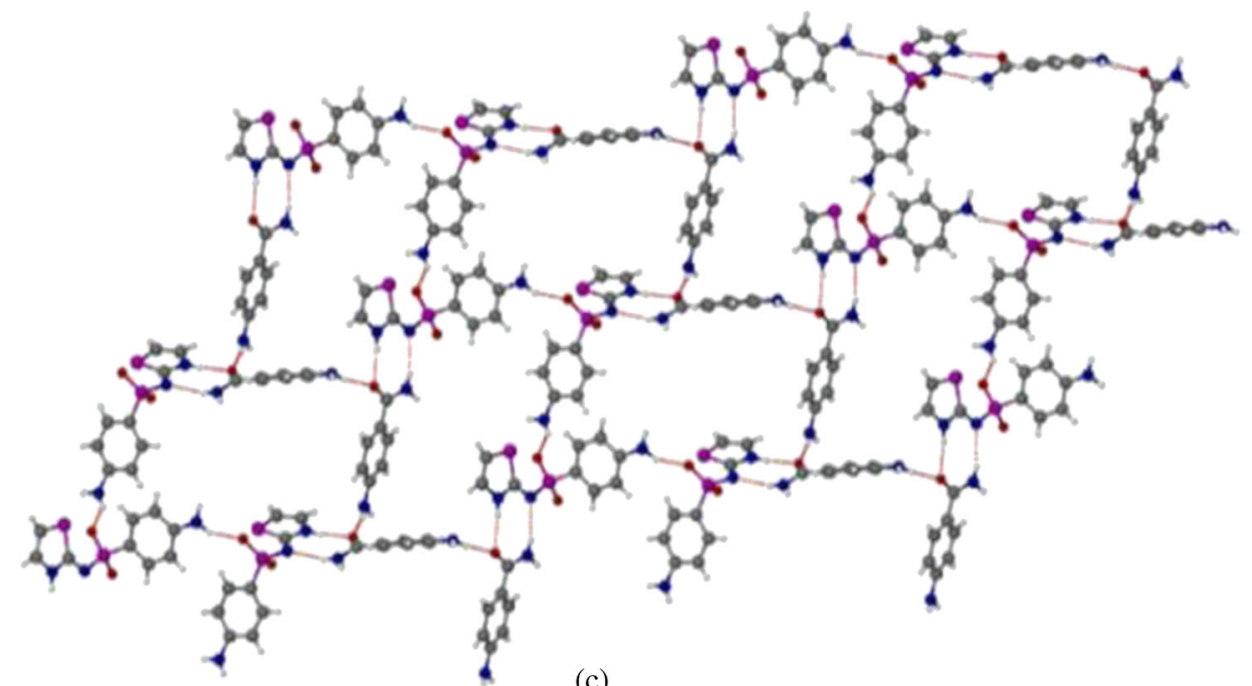

Figure 2. (a) Showing the H-bonding in STZ/4ABM co-crystal. (b) Formation of a cyclic motif via synthon 4 in STZ/4ABM that indeed connects two 2D-sheets. (c) $2 \mathrm{D}$ sheet with parquet floor network.

STZ/DNB salt showed it at $160.37^{\circ} \mathrm{C}$. The observation of only one endothermic transition peak in each case, corresponding to the melting, confirms the absence of impurities or solvents. As no solvent molecules are
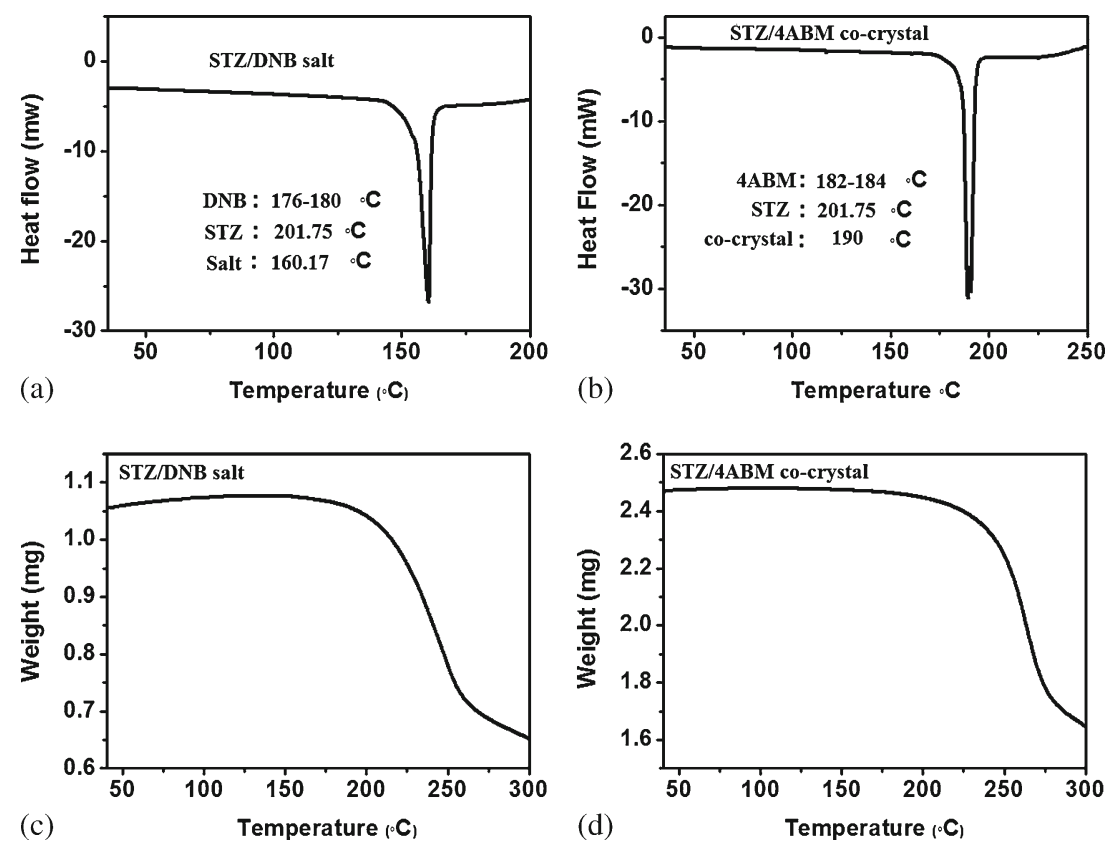

Figure 3. DSC of STZ/DNB (a) and STZ/4ABM (b) respectively. TGA pattern of STZ/DNB (c) and STZ/4ABM (d). 
present, the TGA curves of both the co-crystal and salt showed single weight loss peaks, corresponding to the decomposition (figure $3 \mathrm{c}, \mathrm{d}$ ).

\section{Conclusion}

One new co-crystal and one salt form of sulfathiazole drug with a carboxylic acid and amide are synthesized and characterized by single crystal XRD, DSC, TGA and infrared spectroscopy. Crystal structure analysis revealed that the strong hydrogen bonding groups, namely carboxylate (in STZ/DNB salt) and amide group (in STZ/4ABM) interact with the strong imidine cite. The second strongest groups, $\mathrm{SO}_{2}$ and $\mathrm{NH}_{2}$ from $\mathrm{STZ}$ and/or co-former, interact to form hydrogen bonds. This is consistent with the fact that the strong acceptors prefer strong donors and weak acceptors prefer weak donors. ${ }^{11}$ The present and the structures reported in CSD reveal the strong preference of STZ molecule to exist in imidine tautomeric form.

\section{Supplementary Information}

Infrared spectra, ORTEP representation, crystallographic data, structure refinement parameters and hydrogen bond parameters of STZ co-crystal (STZ/4ABM) and salt (STZ/DNB) are provided in the supplementary information.

\section{References}

1. (a) Desiraju G R 1989 In Crystal Engineering: The Design of Organic Solids (New York: Elsevier); (b) Desiraju G R 2007 Angew. Chem. Int. Ed. 46 8342; (c) Frontiers in Crystal Engineering 2006 E Tiekink E and J J Vittal (Eds.) (UK: Wiley Chichester)

2. (a) Sun C C and H Hou 2008 Cryst. Growth Des. 8 1575; (b) Ghosh S and Reddy C M 2012 Angew. Chem. Int. Ed. 51 10319; (c) Almarsson Ö and Zaworothko M J Chem. Comm. 2041889

3. Desiraju G R 1995 Angew. Chem. Int. Ed. Engl. 34 2311

4. Adsmond D A and Grant D J W 2001 J. Pharm. Sci. 90 2058

5. Ghosh S, Bag P P and Reddy C M 2011 Cryst. Growth Des. 113489

6. Hu Y, Gniado K, Erxleben A and McArdle P 2014 Cryst. Growth Des. 14803

7. Childs S L, Stahly G P and Park A 2007 Mol. Pharmaceutics 4(3) 323

8. Babić S, Horvat J M A, Pavlović M D and Macan K M 2007 Trends in Analytical Chemistry 261043

9. Yangjeh H A, Jenagharad D M and Nooshyar M 2005 Bull. Korean Chem. Soc. 262007

10. Bag P P, Kothur R R and Reddy C M 2014 CrystEnggComm 164706

11. Etter M C and Macdonald J C 1990 Acta Crystallogr. B 46256 